\title{
Differences in Lung Cancer Treatment Preferences Among Oncologists, Patients and Family Members: A Semi-Structured Qualitative Study in China
}

This article was published in the following Dove Press journal: Patient Preference and Adherence

\author{
Xiaoning $\mathrm{He}^{1,2}$ \\ Mengqian Zhang ${ }^{1,2}$ \\ Jing $\mathrm{Wu}^{1,2}$ \\ Song $\mathrm{Xu}$ iD $^{3}$ \\ Xiangli Jiang ${ }^{4}$ \\ Ziping Wang ${ }^{5}$ \\ Shucai Zhang ${ }^{6}$ \\ Feng $\mathrm{Xie}^{7,8}$
}

'School of Pharmaceutical Science and Technology, Tianjin University, Tianjin, People's Republic of China; ${ }^{2}$ Center for Social Science Survey and Data, Tianjin University, Tianjin, People's Republic of China; ${ }^{3}$ Department of Lung Cancer Surgery, Tianjin Key Laboratory of Lung Cancer Metastasis and Tumor Microenvironment, Lung Cancer Institute, Tianjin Medical University General Hospital, Tianjin, People's Republic of China; ${ }^{4}$ Tianjin Medical University Cancer Institute \& Hospital, Tianjin, People's Republic of China; ${ }^{5}$ Department of Medical Oncology, Cancer Institute (Hospital), Chinese Academy of Medical Sciences \& Peking Union Medical College, Beijing, People's Republic of China; 'Department of Medical Oncology, Beijing Chest Hospital, Beijing, People's Republic of China;

${ }^{7}$ Department of Health Research Methods, Evidence and Impact, McMaster University, Hamilton, ON, Canada; ${ }^{8}$ Centre for Health Economics and Policy Analysis, McMaster University, Hamilton, ON, Canada

Correspondence: Jing Wu

School of Pharmaceutical Science and Technology, Tianjin University, No. 92 Weijin Road, Nankai District, Tianjin, 300072, People's Republic of China

Tel +862227405176

Fax +862287401830

Email jingwu@tju.edu.cn
Background: Cancer treatment decision-making often needs to balance benefits, harms, and costs. This study sought to identify the differences in cancer treatment preference among oncologists, patients and their family members in China.

Methods: A semi-structured face-to-face qualitative interview was conducted among oncologists, patients and their family members recruited in four tertiary hospitals in China. The interview guide was developed based on literature review and expert consultation. Participants were asked to indicate their preferences when making lung cancer treatment decisions. All interviews were audio-taped, transcribed verbatim, and thematic analyzed. The preferences were compared among three groups of participants.

Results: A total of 17 participants ( 5 oncologists, 6 dyads of patients and family members) were interviewed between June and July 2019. Five themes, namely, survival benefit, adverse effect/symptom, treatment process, treatment cost, and the impact on daily life were identified. The oncologists and family members gave highest priority on survival benefit, while the patients are concerned most about treatment cost and quality of life.

Conclusion: This study reveals different preferences for cancer treatment among oncologists, patients and their family members in China. Education is needed to empower patients and family members and promote share decision-making in this country.

Keywords: lung cancer, preference, qualitative interview, survival benefit, cost

\section{Introduction}

Lung cancer is the leading cause of cancer incidence and mortality, with 2.1 million new cases and causing 1.76 million deaths worldwide in 2018. In China, lung cancer accounts for $18.1 \%$ of new cancer cases and $24.1 \%$ of cancer deaths. ${ }^{1,2}$ The 5-year survival rate among patients with lung cancer was estimated at $19.8 \%$ in China. $^{3}$ During the past 20 years, target therapies and immunotherapies have greatly improved the prognoses and outcomes of cancer patients. ${ }^{4,5}$ Nevertheless, these new therapies also impose significant burdens on patients including adverse events, mental stresses, and financial worries. ${ }^{6,7}$ When making treatment decisions, a trade-off between treatment benefits (eg, extended survival) and burdens (eg, adverse effect, cost) has to be made.

As we are thriving to establish a patient-centered healthcare system, clinical decision-making is shifting from the paternalistic model in which physicians dominated the treatment decision to shared decision-making between physicians and $_{\text {patients. }}^{8-10}$ However, many patients may still not feel comfortable of 
expressing their preference which limits the development and implementation of sharing decision-making. ${ }^{11}$ In China, family members are playing an important role in making treatment decisions. ${ }^{12}$ Moreover, family members may discuss the disease condition and treatment choice with oncologists, ${ }^{13}$ without involving the patient. ${ }^{14}$ As a result, some cancer patients are not even aware of the diagnosis. ${ }^{15}$ However, oncologists and family members may perceive the needs and preferences for treatments differently from the patient. Studies conducted in Italy and Australia reported that lung cancer patients were more willing to receive a treatment with small survival benefit than what their oncologists expected. ${ }^{16,17}$ Existing studies comparing the preferences between oncologists and lung cancer patients ${ }^{16-18}$ often focused on the attitudes/preferences for specific treatment regimens such as adjuvant chemotherapy, or treatment attributes such as overall survival (OS) and treatment convenience. No preference study has considered overall treatment benefits and risks for lung cancer. Moreover, little research has been conducted in China to understand the preferences of family members of cancer patients. In order to improve lung cancer treatment decision-making in China, we conducted a qualitative study to investigate and compare lung cancer treatment preferences among oncologists, patients and family members.

\section{Methods}

Qualitative face-to-face semi-structured interviews were conducted separately with lung cancer specialists, patients and their family members. Oncologists, patients and family members were asked to rank the factors mentioned at the end of the interview. A number of themes were developed through thematic analysis. The rank of different themes was concluded to ascertain preference differences.

\section{Participants}

Lung cancer patients, their attending oncologists and family members were recruited in four tertiary hospitals in Tianjin and Beijing, two large cities in China, between June and July 2019. The inclusion criteria for patients were age $\geq 18$, diagnosed with lung cancer, currently on treatment, and without communication barriers. We used the quota sampling to ensure there was a reasonable diversity among participants in each group, for example, years of practice for oncologist, and disease stage and urban vs rural residents (the specific quota could be seen in Supplementary Table 1). The inclusion criteria for oncologists are having lung cancer treatment experience and meeting quotas in terms of gender and academic title. In order to meet the maximum variation principle, ${ }^{19}$ each quota should have at least one participant. One family member of each participating patients was invited to the interview as well.

\section{Semi-Structured Interview}

An interview guide was developed based on a literature review and feedback from pilot interviews with two specialists in lung cancer (full guide could be seen in Supplementary Materials). By following the guide, the interview consisted of three steps. First, basic demographic characteristics of the participants were collected. Second, open-ended questions were used to ask participants to talk about their communication process for treatment decision-making, factors they considered important when selecting treatment regimens, and their experiences and expectations of cancer treatments received. Third, the interviewer went over the information collected with the participant to ensure all was correct and accurate. And the participant was asked to rank the factors they mentioned from most to least important, and state the reasons.

\section{Data Collection}

Eligible oncologists in the participating hospitals were first approached. Through the referral of the oncologists, the patients and family members were contacted for interview when the patient received treatment in the hospital. All participants provided the informed consent prior to the interview. One-to-one interviews in Chinese were undertaken in the private rooms of the hospitals by two researchers (XH and MZ). The Institutional Review Board of Tianjin University and both participating hospitals approved this study. The interviews followed the principles of the Declaration of Helsinki.

\section{Data Analysis}

All interviews were audiotaped and transcribed verbatim in Chinese. Thematic analysis was used to analyze the data. The important factors in decision-making described by participants were coded from the electronic transcript. We also calculated the frequency of every code. Inductive themes were then identified. The overall ranking of factors was derived by averaging over the rankings made by all participants in each group. The codes and themes were translated into English and further audited by a bilingual 
reviewer. We compared the themes and corresponding rankings among the three groups.

\section{Results}

\section{Characteristics of Participants}

A total of 17 participants were interviewed, including five lung cancer oncologists, six dyads of lung cancer patients and their family members. Oncologists and patients met the prespecified quota requirements (Supplementary Table 2). As shown in Table 1, participating oncologists included resident physicians $(\mathrm{n}=2)$, attending physicians $(n=2)$ and associate chief physician $(n=1)$ in the surgical or medical oncology department, and their practicing years ranged from 5 to 22 years. Demographics of patients and family members are described in Table 2. The age of patient participants ranged from 35 to 66 years, with a median age of 56 years. Patients were in locally advanced stage $(n=2)$ or advanced stage $(n=4)$ of lung cancer, and their duration of illness varied from 0.5 to 24 months. Their monthly income ranged from $\leq \mathrm{CNY} 2,000$ (US $\$ 300$ ) to $>$ CNY10,000 (US\$1501). Most patients live in urban areas $(n=4)$ and have the Urban Employee Basic Medical Insurance $(\mathrm{UEBMI})^{20} \quad(\mathrm{n}=5)$. Patients had received a wide range of treatments, including surgical resection, chemotherapy, targeted therapy and immune therapy. Participating family members are patients' spouses $(n=4)$ or adult children $(n=2)$. The detailed information for each participant is shown in Supplementary $\underline{\text { Tables } 3}$ and $\underline{4}$.

Table I Demographics of Oncologists

\begin{tabular}{|l|c|}
\hline Basic Characteristics & Oncologists \\
\hline Age, median (MIN-MAX) & $33(28-47)$ \\
\hline $\begin{array}{l}\text { Gender, N (\%) } \\
\text { Male }\end{array}$ & $2(40)$ \\
Female & $3(60)$ \\
\hline Department, N (\%) & \\
Surgical Oncology Department & $\mathrm{I}(20)$ \\
Medical Oncology Department & $4(80)$ \\
\hline Academical title, N (\%) & $2(40)$ \\
Associate chief physician & $3(40)$ \\
Resident physician & $\mathrm{I}(20)$ \\
\hline Attending physician & $\mathrm{II} .2(5-22)$ \\
\hline Practicing years, mean (MIN-MAX) & I24 (60-300) \\
\hline No. of patients treated (case/month), mean (MIN-MAX)
\end{tabular}

\section{Themes Related to Treatment Preferences}

A total of 84 codes were identified and grouped into five themes, namely, survival benefit, adverse effect/symptom, treatment process, treatment cost, and the impact on daily life. Table 3 shows the explanations of these themes and the codes with frequency. The survival benefit theme includes 14 codes and the most frequently mentioned was "overall survival/survival time $(n=12)$ ". There are 54 codes related to adverse effect/symptom, which are grouped into sub-themes according to the site of adverse effects or symptoms occurred. The treatment process theme includes seven codes, where "mode of administration $(\mathrm{n}=8)$ " was the most frequently mentioned. The treatment cost theme has only two codes: "costs" and "costeffectiveness". Seven codes are related to the impact on daily life with "appetite $(n=8)$ " being the most frequent one.

\section{Difference in Treatment Preferences Among Oncologists, Patients and Family Members} Survival vs Cost

The oncologists and five family members all considered survival benefit as the first priority. One oncologist indicated that "From a medical point of view, the maximization of treatment effect is definitely the most important." (D1), "Treatment effect is our key concern. The primary objective is to control the disease and prolong overall survival." (D5). Family members expressed that "[When making decision] The most concern is survival. Nothing is more important than being alive for a cancer patient." (R1), "I wish the treatment could control the disease and keep him alive." (R5).

In contrast, survival benefit was considered most important by two patients versus cost by the remaining four patients. A patient stated that

Life is the first consideration. While under this circum-
stance, we are trading our savings for more life years. The
treatment cost will impose a huge economic burden on my
family that is the biggest concern for me. Personally, I
prefer receiving no treatment and maintaining the status
quo as long as possible. (P2)

"[For lung cancer treatment] My first consideration is cost. I will never allow my family fall into poverty because of this disease." (P4). One patient mentioned 
Table 2 Demographics of Patients and Family Members

\begin{tabular}{|c|c|c|}
\hline Basic Characteristics & Patients & $\begin{array}{c}\text { Family } \\
\text { Members }\end{array}$ \\
\hline Age, median (MIN-MAX) & $56(35-66)$ & $45(35-67)$ \\
\hline \multicolumn{3}{|l|}{ Gender, N (\%) } \\
\hline Male & $4(67)$ & I (I7) \\
\hline Female & $2(33)$ & $5(83)$ \\
\hline \multicolumn{3}{|l|}{ Education degree, $\mathrm{N}(\%)$} \\
\hline College and above & $3(50)$ & $4(67)$ \\
\hline Middle school and below & $3(50)$ & $2(33)$ \\
\hline \multicolumn{3}{|l|}{ Employment status, N (\%) } \\
\hline Employed & $2(33)$ & $3(50)$ \\
\hline Retired & $3(50)$ & I (I7) \\
\hline Unemployed & I (I7) & $2(33)$ \\
\hline \multicolumn{3}{|l|}{ Individual income (CNY/month), N (\%) } \\
\hline$>10,000$ & $\mathrm{I}(\mathrm{I7})$ & $3(50)$ \\
\hline $500 I-10,000$ & $2(33)$ & $0(0)$ \\
\hline $200 I-5000$ & $2(33)$ & $\mathrm{I}(\mathrm{I7})$ \\
\hline$\leq 2000$ & $\mathrm{I}(\mathrm{I7})$ & $2(33)$ \\
\hline \multicolumn{3}{|l|}{ Registered residence, $\mathrm{N}(\%)$} \\
\hline Urban & $4(67)$ & $4(67)$ \\
\hline Rural & $2(33)$ & $2(33)$ \\
\hline Insurance N (\%) & & - \\
\hline UEBMI & $5(83)$ & \\
\hline URRBMI & $\mathrm{I}(\mathrm{I7})$ & \\
\hline \multicolumn{3}{|l|}{ Stage, N (\%) } \\
\hline Locally advanced & $2(33)$ & \\
\hline Advanced & $4(67)$ & \\
\hline Disease duration (month), median (MIN-MAX) & $11.9(0.5-24)$ & \\
\hline \multicolumn{3}{|l|}{ Treatment history, N (\%) } \\
\hline Basic therapy & $I(I 7)$ & \\
\hline Surgery & $\mathrm{I}(\mathrm{I7})$ & \\
\hline Chemotherapy & $3(50)$ & \\
\hline Targeted therapy & $2(33)$ & \\
\hline Immune therapy & $I(I 7)$ & \\
\hline Role of relative, $\mathrm{N}(\%)$ & - & \\
\hline Parent-child relationship & & $2(33)$ \\
\hline Conjugal relationship & & $4(67)$ \\
\hline
\end{tabular}

Abbreviations: UEBMI, Urban Employee Basic Medical Insurance; URRBMI, Urban and Rural Resident Basic Medical Insurance.

"cost-effectiveness". "[When choosing a treatment] Costeffectiveness should be within a reasonable range, otherwise, this treatment would not be acceptable." (P4).

The oncologists were less concerned about the cost and ranked it as the fourth important factor. An oncologist explained that
For targeted therapy, most drugs could be compensated by medical insurance, and almost $90 \%$ patients could afford. For new developed and high-priced immunotherapy, 30\%$40 \%$ patients may not be able to afford. (O3)

Similar preferences were also expressed by the family members who ranked the cost as the second important factor. 
Table 3 The Explanations of Every Theme and Their Codes with Frequency

\begin{tabular}{|c|c|c|c|c|c|c|c|}
\hline \multicolumn{2}{|l|}{ Theme } & No. & Codes & $\begin{array}{l}\text { Total } \\
\text { Frequency }\end{array}$ & $\begin{array}{l}\text { Oncologists' } \\
\text { Frequency }\end{array}$ & $\begin{array}{l}\text { Patients' } \\
\text { Frequency }\end{array}$ & $\begin{array}{c}\text { Family } \\
\text { Members' } \\
\text { Frequency }\end{array}$ \\
\hline \multirow{14}{*}{\multicolumn{2}{|c|}{$\begin{array}{l}\text { Survival benefit: Patient health outcomes and } \\
\text { clinical benefits }\end{array}$}} & 1 & Overall survival (OS)/survival time & 12 & 4 & 3 & 5 \\
\hline & & 2 & Progress/control/partial remission & 10 & 3 & 4 & 4 \\
\hline & & 3 & Progress-free survival (PFS) & 4 & 4 & 0 & 0 \\
\hline & & 4 & Symptom decrease & 4 & 1 & 2 & 1 \\
\hline & & 5 & Relapse & 3 & 1 & 1 & 1 \\
\hline & & 6 & Remission rate & 3 & 3 & 0 & 0 \\
\hline & & 7 & Recovery rate & 2 & 1 & 0 & 1 \\
\hline & & 8 & Median survival rate & 1 & 1 & 0 & 0 \\
\hline & & 9 & Overall survival rate & 1 & 1 & 0 & 0 \\
\hline & & 10 & Disease control rate (DCR) & 1 & 1 & 0 & 0 \\
\hline & & 11 & Response duration & 1 & 1 & 0 & 0 \\
\hline & & 12 & Effective duration & 1 & 1 & 0 & 0 \\
\hline & & 13 & Transfer & 1 & 0 & 0 & 1 \\
\hline & & 14 & Prognosis & 1 & 1 & 0 & 0 \\
\hline \multirow{36}{*}{$\begin{array}{l}\text { Adverse effect/symptom: } \\
\text { Treatment induced adverse } \\
\text { events or any discomfort } \\
\text { resulting from disease itself }\end{array}$} & \multirow{4}{*}{$\begin{array}{l}\text { Alimentary } \\
\text { system }\end{array}$} & 1 & Emesis & 8 & 4 & 2 & 2 \\
\hline & & 2 & Nausea & 5 & 3 & 1 & 1 \\
\hline & & 3 & Diarrhea & 5 & 3 & 1 & 1 \\
\hline & & 4 & Peptic ulcer & 1 & 1 & 0 & 0 \\
\hline & \multirow[t]{7}{*}{ Skin } & 5 & Rash & 4 & 3 & 0 & 1 \\
\hline & & 6 & Paronychia & 3 & 2 & 0 & 1 \\
\hline & & 7 & Irritability & 2 & 2 & 0 & 0 \\
\hline & & 8 & Dental ulcer & 2 & 0 & 0 & 2 \\
\hline & & 9 & Dermatitis & 1 & 0 & 0 & 1 \\
\hline & & 10 & Pruritus & 1 & 1 & 0 & 0 \\
\hline & & II & Ecchymosis & 1 & 1 & 0 & 0 \\
\hline & \multirow[t]{8}{*}{ Immune related } & 12 & Pneumonia & 4 & 4 & 0 & 0 \\
\hline & & 13 & Myocarditis & 3 & 3 & 0 & 0 \\
\hline & & 14 & Hypophysitis & 2 & 2 & 0 & 0 \\
\hline & & 15 & Liver injury & 2 & 2 & 0 & 0 \\
\hline & & 16 & Enteritis & 2 & 2 & 0 & 0 \\
\hline & & 17 & Colitis & 1 & 1 & 0 & 0 \\
\hline & & 18 & Thyroid alteration & I & 1 & 0 & 0 \\
\hline & & 19 & Skin injury & 1 & 1 & 0 & 0 \\
\hline & \multirow{11}{*}{$\begin{array}{c}\text { Respiratory } \\
\text { system }\end{array}$} & 20 & Shortness of breath & 4 & 2 & 0 & 2 \\
\hline & & 21 & Cough & 3 & 1 & 1 & 1 \\
\hline & & 22 & Asthma & 2 & 0 & 1 & 1 \\
\hline & & 23 & Pulmonary infection & 2 & 2 & 0 & 0 \\
\hline & & 24 & Expectoration & 1 & 1 & 0 & 0 \\
\hline & & 25 & Empyema & $\mathrm{I}$ & 1 & 0 & 0 \\
\hline & & 26 & Hemothorax & 1 & 1 & 0 & 0 \\
\hline & & 27 & Pneumothorax & $\mathrm{I}$ & 1 & 0 & 0 \\
\hline & & 28 & Chest pain & 1 & 1 & 0 & 0 \\
\hline & & 29 & Interstitial pneumonia & 1 & 1 & 0 & 0 \\
\hline & & 30 & Radiation pneumonia & 1 & 1 & 0 & 0 \\
\hline & \multirow[t]{6}{*}{ Blood system } & 31 & Myelosuppression & 4 & 4 & 0 & 0 \\
\hline & & 32 & Bleeding & 3 & 2 & 0 & 1 \\
\hline & & 34 & Phlebitis & 2 & 2 & 0 & 0 \\
\hline & & 33 & Thrombocytopenia & 1 & I & 0 & 0 \\
\hline & & 35 & Leukopenia & $\mathrm{I}$ & 1 & 0 & 0 \\
\hline & & 36 & Leukocytosis & 1 & 0 & 1 & 0 \\
\hline
\end{tabular}

(Continued) 
Table 3 (Continued).

\begin{tabular}{|c|c|c|c|c|c|c|}
\hline Theme & \multirow{2}{*}{$\begin{array}{l}\text { No. } \\
37\end{array}$} & Codes & $\begin{array}{c}\text { Total } \\
\text { Frequency }\end{array}$ & $\begin{array}{l}\text { Oncologists' } \\
\text { Frequency }\end{array}$ & $\begin{array}{l}\text { Patients' } \\
\text { Frequency }\end{array}$ & $\begin{array}{c}\text { Family } \\
\text { Members' } \\
\text { Frequency } \\
\end{array}$ \\
\hline Endocrine & & Decreased pituitary function & 1 & 1 & 0 & 0 \\
\hline system & 38 & Hypothyroidism & 1 & 1 & 0 & 0 \\
\hline & 39 & Hyperthyroidism & 1 & 1 & 0 & 0 \\
\hline & 40 & Proteinuria & 1 & 1 & 0 & 0 \\
\hline Nervous & 41 & Neurotoxicity & 1 & 1 & 0 & 0 \\
\hline system & 42 & Peripheral nerve injury & 1 & 1 & 0 & 0 \\
\hline Circulatory & 43 & Thrombus & 1 & 1 & 0 & 0 \\
\hline system & 44 & Hypertension & 1 & 1 & 0 & 0 \\
\hline Other organ & 45 & Liver and kidney damage & 3 & 3 & 0 & 0 \\
\hline damage & 46 & Cardiac impairment & 3 & 3 & 0 & 0 \\
\hline & 47 & Liver injury & 2 & 2 & 0 & 0 \\
\hline & 48 & Lung function injury & 1 & 0 & 0 & 1 \\
\hline Other & 49 & Hair Loss & 8 & 3 & 3 & 2 \\
\hline symptoms & 50 & Fatigue & 7 & 2 & 2 & 3 \\
\hline & 51 & Pain & 6 & 1 & 2 & 3 \\
\hline & 52 & Dizziness & 3 & I & 1 & 1 \\
\hline & 53 & Paropsia & 3 & 2 & 1 & 0 \\
\hline & 54 & Headache & 2 & 1 & 0 & 1 \\
\hline \multirow{7}{*}{$\begin{array}{l}\text { Impact on quality of life: Influences developed by } \\
\text { treatment on daily activities or physical conditions }\end{array}$} & 1 & Appetite & 8 & 2 & 1 & 1 \\
\hline & 2 & Social activities & 4 & 1 & 2 & 1 \\
\hline & 3 & Daily activities & 3 & 0 & 0 & 3 \\
\hline & 5 & Emaciation & 2 & 0 & 2 & 0 \\
\hline & 6 & Physical deterioration & 2 & 0 & 0 & 2 \\
\hline & 4 & Sleep quality & 1 & 1 & 0 & 0 \\
\hline & 7 & Family activities & 1 & 1 & 0 & 0 \\
\hline \multirow[t]{7}{*}{ Treatment process: Procedure relevant factors } & 1 & Drug administration way & 8 & 5 & I & 2 \\
\hline & 2 & Hospital level and medical skill & 5 & 1 & 1 & 3 \\
\hline & 3 & Hospitalization time & 4 & 3 & 1 & 0 \\
\hline & 4 & Treatment cycle & 3 & 3 & 0 & 0 \\
\hline & 5 & Waiting time & 3 & 1 & 1 & 1 \\
\hline & 6 & Communication with physicians & 2 & 0 & 2 & 0 \\
\hline & 7 & Convenience of treatment & 1 & 1 & 0 & 0 \\
\hline \multirow{2}{*}{$\begin{array}{l}\text { Treatment cost: All treatment-related expenses } \\
\text { incurred during treatment, including examination } \\
\text { cost, hospital cost, drug cost, etc. }\end{array}$} & 1 & Cost & 17 & 5 & 6 & 6 \\
\hline & 2 & Cost performance & 1 & 0 & 1 & 0 \\
\hline
\end{tabular}

Cost is not a big problem. If our salaries are not enough, we can sell our house property. Life is meaningless without your loved one. We will continue the treatment no matter how much it will spend. (F6)

Treatment cost is not a main factor for now. The drugs in first course of treatment will be covered by medical insurance. And the subsequent treatment could almost be afforded, even without the insurance coverage. (F4)

\section{Adverse Events/Symptoms and Quality of Life}

Adverse events/symptoms and quality of life are important factors for patients when making treatment decisions. One patient expressed his worry about adverse events before receiving treatment,

I am very concerned about the adverse effects. I was told that the [chemotherapy] treatment always has side effects, 
losing hair and weight. It is horrible to experience these and many people cannot bear. (P1)

Another patient who was sensitive to adverse events or symptoms expressed a stronger worry, "When I was in chemotherapy, I almost gave up. I went through four treatment cycles and the adverse events made me want to die." (P5). This patient also described the impacts of treatments on his quality of life, "After a cycle of treatment, I couldn't get out of bed nearly for three days. I cannot event take a sip of water, and nearly ate nothing for one week." (P5). Patients would reject some effective but painful treatments, avoiding physical inconveniences, psychological discomfort, and dignity loss. One patient said

The second important consideration is the quality of my daily life. The length of life is determined by the quality of life. Better quality of life is more important than a longer survival. (P4)

For the oncologists, adverse events/symptoms and quality of life were ranked as the secondary and third considerations, while life-threatening adverse events were most concerning. An oncologist said that "From my perspective, I will focus on those serious adverse events or symptoms. Mild events are either transient or can be controlled by medications." (O2). Another oncologist said "Quality of life is also an important indicator of treatment effect, which is however sometimes neglected by many physicians." (D1).

Family members paid less attention to adverse events/ symptoms and quality of life by ranking them as the fifth and fourth factors, respectively. One said that "occurrence of an adverse event is a probabilistic question. And it may not be predicted exactly." (F4). Another family member mentioned that "I do not care adverse effects. My father is a very brave man. He also knowns potential adverse effects and he can bear." (F1). Another family member expressed that

Among the options of 5 years survival with good quality of life and 10 years survival with poor quality of life, the latter one is definitely selected. Being alive is an essential precondition before we consider quality of life. (F1)

\section{Treatment Process}

Treatment process was also considered but ranked last consistently by all participants. An oncologist mentioned that "The length of hospital stay is under my consideration. 'Quick recovery' with shorter hospital stays will bring benefits to the patients." (D1). One family member said "Medical care capacity is also under my consideration. Oncologists in high level hospitals may provide better treatment." (C6).

\section{Discussion}

Our study found that cost, adverse effects/symptoms, and impact on quality of life are the most important factors for the patients compared with survival by oncologists and family members when considering cancer treatment in China. This qualitative study provides an in-depth understanding of the differences in treatment preferences between patients and their physicians and family members.

Survival benefit is the most important factor for selecting cancer treatments by the oncologists. There are similar findings from previous studies conducted in China, the USA, and Japan. ${ }^{21-23}$ This is shared by family members who hope their loved ones could live longer. ${ }^{24,25}$ Chinese culture is deeply shaped by Confucian philosophy in which family is the core element of society. Caring for elderly parents is a key definition in Chinese filial piety. ${ }^{26}$ Therefore, it is not surprising to observe this preference among family members.

Indeed, the rising cost of cancer treatments is imposing a significant burden on cancer patients worldwide. ${ }^{27,28} \mathrm{~A}$ study by the Association of Oncology Social Work indicates that $40 \%$ of cancer patients report that the cost of therapy in the last year used up all their savings. ${ }^{29}$ Lang found that the willingness to pay for lung cancer treatments by Chinese patients was lower than the actual price of the treatment. ${ }^{30}$ However, previous preference studies have been focusing on survival, adverse events and treatment process, rather than cost. ${ }^{18,31,32}$ But cost is an important factor in understanding the patient's treatment preference in China due to varied public insurance coverage and the copayment by Chinese patients.

We found that quality of life is a key factor when making treatment decisions for Chinese patients. There were similar findings in western countries. ${ }^{33-35}$ Improvement in quality of life has been increasingly recognized as an important outcome in oncology randomized controlled trials $(\mathrm{RCTs})^{36,37}$ and clinical guidelines. $^{38}$

Difference in cancer treatment preferences between patients and their physicians and family members highlights the need and importance for promoting shared decision-making in China. The awareness of patient-centered model among Chinese health care professionals has been 
improved noticeably that they stated patient preference is more important in decision-making. Education is needed to make patients and family members aware of the difference in their preference and the importance of engaging patients in the decision-making. Physicians could play an important role in promoting this by encouraging patients and family members to actively participate in the decisionmaking. Social media could be another means to improve the awareness of the concept of shared decision-making among the general public. ${ }^{39}$

To promote shared decision-making, family members' role also should be guided to change from the direct surrogates to helpers of patients. Their over-involvement may overstep and infringe upon the patient's role in decision-making, despite with good intentions. As one patient in the interview claimed, "I am entitled to be informed all of the alternative treatments before they made the decision. This is my life". Family members may also obscure or repress patients' preference and unduly pressured patients to adopt their own preferences. ${ }^{40}$ Some patients would not express their real preference, in fear of letting down family members' expectations or imposing burdens to the family.

The major limitation of this study is the small sample size. We experienced difficulty in recruiting patients and family members despite the effort. This small sample size also limited the representativeness even with the quota sampling. All of the participants in our study were recruited from tertiary hospitals in Beijing and Tianjin, which are both megacities with highly economic and medical development in north China. It is not clear how similar or different the treatment preferences are among those from less developed places.

\section{Conclusion}

This study reveals different preferences for cancer treatment between oncologists, patients and their family members in China. Education is needed to empower patients and family members and promote shared decision-making in this country.

\section{Ethics Approval and Informed Consent}

The study was performed in accordance with the Declaration of Helsinki. Informed consent was obtained from all individual participants included in the study. Ethical approval was obtained by the Safety and Ethics
Committee of School of Pharmaceutical Science and Technology in Tianjin University and all research hospitals (Tianjin Medical University General Hospital and Tianjin Medical University Cancer Institute \& Hospital).

\section{Author Contributions}

All authors made a significant contribution to the work reported, whether that is in the conception, study design, execution, acquisition of data, analysis and interpretation, or in all these areas; took part in drafting, revising or critically reviewing the article; gave final approval of the version to be published; have agreed on the journal to which the article has been submitted; and agree to be accountable for all aspects of the work.

\section{Funding}

This study was funded by the National Natural Science Foundation of China (No. 71673197 \& No. 71804122).

\section{Disclosure}

The authors declare that they have no competing interests.

\section{References}

1. Bray F, Ferlay J, Soerjomataram I, Siegel RL, Torre LA, Jemal A. Global cancer statistics 2018: GLOBOCAN estimates of incidence and mortality worldwide for 36 cancers in 185 countries. CA Cancer J Clin. 2018;68(6):394-424. doi:10.3322/caac.21492

2. World Health Organization. International agency for research on cancer. China fact sheets; 2018. Available from: https://gco.iarc.fr/ today/data/factsheets/populations/160-china-fact-sheets.pdf. Accessed March 26, 2021.

3. Allemani C, Matsuda T, Di Carlo V, et al. Global surveillance of trends in cancer survival 2000-14 (CONCORD-3): analysis of individual records for 37513025 patients diagnosed with one of 18 cancers from 322 population-based registries in 71 countries. Lancet. 2018;391(10125):1023-1075.

4. Yang S, Zhang Z, Wang Q. Emerging therapies for small cell lung cancer. J Hematol Oncol. 2019;12(1):47. doi:10.1186/s13045-0190736-3

5. Duma N, Santana-Davila R, Molina JR. Non-small cell lung cancer: epidemiology, screening, diagnosis, and treatment. Mayo Clin proc. 2019;94(8):1623-1640. doi:10.1016/j.mayocp.2019.01.013

6. Steven A, Fisher SA, Robinson BW. Immunotherapy for lung cancer. Respirology. 2016;21(5):821-833. doi:10.1111/resp.12789

7. Ricciardi S, Tomao S, de Marinis F. Toxicity of targeted therapy in non-small-cell lung cancer management. Clin Lung Cancer. 2009;10 (1):28-35. doi:10.3816/CLC.2009.n.004

8. Barry MJ, Edgman-Levitan S. Shared decision making-pinnacle of patient-centered care. $N$ Engl $J$ Med. 2012;366(9):780-781. doi:10.1056/NEJMp1109283

9. Frosch DL, Kaplan RM. Shared decision making in clinical medicine: past research and future directions. Am J Prev Med. 1999;17 (4):285-294. doi:10.1016/S0749-3797(99)00097-5

10. Emanuel EJ, Emanuel LL. Four models of the physician-patient relationship. JAMA. 1992;267(16):2221-2226. doi:10.1001/ jama.1992.03480160079038 
11. Ting X, Yong B, Yin L, Mi T. Patient perception and the barriers to practicing patient-centered communication: a survey and in-depth interview of Chinese patients and physicians. Patient Educ Couns. 2016;99(3):364-369. doi:10.1016/j.pec.2015.07.019

12. Rui D. A family-oriented decision-making model for human research in Mainland China. J Med Philos. 2015;40(4):400-417. doi:10.1093/ jmp/jhv013

13. Lin ML, Huang CT, Chen CH. Reasons for family involvement in elective surgical decision-making in Taiwan: a qualitative study. $J$ Clin Nurs. 2017;26(13-14):1969-1977. doi:10.1111/jocn.13600

14. Hobbs GS, Landrum MB, Arora NK, et al. The role of families in decisions regarding cancer treatments. Cancer. 2015;121(7):10791087. doi:10.1002/cncr.29064

15. Hahne J, Liang T, Khoshnood K, Wang X, Li X. Breaking bad news about cancer in China: concerns and conflicts faced by doctors deciding whether to inform patients. Patient Educ Couns. 2020;103 (2):286-291. doi:10.1016/j.pec.2019.08.022

16. Pacchiana MV, Capelletto E, Carnio S, et al. Patients' attitudes and physicians' perceptions toward maintenance therapy for advanced non-small-cell lung cancer: a multicenter Italian survey. Clin Lung Cancer. 2017;18(4):381-387. doi:10.1016/j.cllc.2016.10.002

17. Blinman P, Hughes B, Crombie C, et al. Patients' and doctors' preferences for adjuvant chemotherapy in resected non-small-cell lung cancer: what makes it worthwhile? Eur $j$ Cancer. 2015;51 (12):1529-1537. doi:10.1016/j.ejca.2015.05.022

18. McMullen S, Hess LM, Kim ES, et al. Treatment decisions for advanced non-squamous non-small cell lung cancer: patient and physician perspectives on maintenance therapy. patient. 2019;12 (2):223-233. doi:10.1007/s40271-018-0327-3

19. Teddlie C, Yu F. Mixed methods sampling. J Mix Methods Res. 2016;1:77-100. doi:10.1177/1558689806292430

20. Sun Y, Gregersen H, Yuan W. Chinese health care system and clinical epidemiology. Clin Epidemiol. 2017;9:167-178. doi:10.2147/CLEP. S106258

21. Sun H, Wang H, Shi L, et al. Physician preferences for chemotherapy in the treatment of non-small cell lung cancer in China: evidence from multicentre discrete choice experiments. BMJ Open. 2020;10 (2):e032336. doi:10.1136/bmjopen-2019-032336

22. Gonzalez JM, Doan J, Gebben DJ, Boeri M, Fishman M. Comparing the relative importance of attributes of metastatic renal cell carcinoma treatments to patients and physicians in the united states: a discrete-choice experiment. PharmacoEconomics. 2018;36(8):973986. doi:10.1007/s40273-018-0640-7

23. Bolt T, Mahlich J, Nakamura Y, Nakayama M. Hematologists' preferences for first-line therapy characteristics for multiple myeloma in Japan: attribute rating and discrete choice experiment. Clin Ther. 2018;40(2):296-308.e292. doi:10.1016/j.clinthera.2017.12.012

24. Wieland J, Hoppe BS, Rausch-Osian SM, et al. Survivor and caregiver expectations and preferences regarding lung cancer treatment. Int j Part Ther. 2019;6(2):42-49. doi:10.14338/IJPT-19-00072.1

25. Jen W-Y, Yoong J, Liu X, Tan MSY, Chng WJ, Chee Y-L. Qualitative study of factors affecting patient, caregiver and physician preferences for treatment of myeloma and indolent lymphoma. Patient Prefer Adherence. 2020;14:301-308. doi:10.2147/PPA.S241340
26. Leng J, Lui F, Chen A, Huang X, Gany F. Adapting meaningcentered psychotherapy in advanced cancer for the Chinese immigrant population. J Immigrant Minority Health. 2017;20(11 Suppl):1-7.

27. Somers C, Chimonas S, McIntosh E, Kaltenboeck A, Briggs A, Bach P. Using nominal group technique to identify key attributes of oncology treatments for a discrete choice experiment. MDM Policy Pract. 2019;4(1):2381468319837925. doi:10.1177/2381468319837925

28. Lee JY, Kim K, Lee YS, et al. Treatment preferences of advanced ovarian cancer patients for adding bevacizumab to first-line therapy. Gynecol Oncol. 2016;143(3):622-627. doi:10.1016/j.ygyno.201 6.10 .021

29. Smith SK, Nicolla J, Zafar SY. Bridging the gap between financial distress and available resources for patients with cancer: a qualitative study. J Oncol Pract. 2014;10(5):e368-e372. doi:10.1200/ JOP.2013.001342

30. Lang HC. Willingness to pay for lung cancer treatment. Value Health. 2010;13(6):743-749. doi:10.1111/j.1524-4733.2010.00743.x

31. Schmidt K, Damm K, Vogel A, et al. Therapy preferences of patients with lung and colon cancer: a discrete choice experiment. Patient Prefer Adherence. 2017;11:1647-1656. doi:10.2147/PPA.S138863

32. Muhlbacher AC, Bethge S. Patients' preferences: a discrete-choice experiment for treatment of non-small-cell lung cancer. Eur J Health Econ. 2015;16(6):657-670. doi:10.1007/s10198-014-0622-4

33. Bridges J, Cruz M, Pavilack M. et al. Patient preferences for attributes of tyrosine kinase inhibitor treatments for EGFR mutationpositive non-small-cell lung cancer. Future Oncol;2019. 15. doi: 10.2217/fon-2019-0396

34. Tong BC, Wallace S, Hartwig MG, D’Amico TA, Huber JC. Patient preferences in treatment choices for early-stage lung cancer. Ann Thorac Surg. 2016;102(6):1837-1844. doi:10.1016/j.athoracsur.20 16.06 .031

35. Gerber DE, Hamann HA, Rasco DW, Woodruff S, Lee SJ. Patient comprehension and attitudes toward maintenance chemotherapy for lung cancer. Patient Educ Couns. 2012;89(1):102-108. doi:10.1016/j. pec. 2012.04 .013

36. Polanski J, Jankowska-Polanska B, Rosinczuk J, Chabowski M, Szymanska-Chabowska A. Quality of life of patients with lung cancer. Onco Targets Ther. 2016;9:1023-1028. doi:10.2147/OTT. S100685

37. Gralla RJ, Griesinger F. Interpreting clinical trials in lung cancer: impact of methodology and endpoints. J Thorac Oncol. 2007;2(Suppl 2):S51-S58. doi:10.1097/01.JTO.0000269734.27047.3e

38. Camps C, Del Pozo N, Blasco A, Blasco P, Sirera R. Importance of quality of life in patients with non-small-cell lung cancer. Clin Lung Cancer. 2009;10(2):83-90. doi:10.3816/CLC.2009.n.010

39. Longtin Y, Sax H, Leape LL, Sheridan SE, Donaldson L, Pittet D. Patient participation: current knowledge and applicability to patient safety. Mayo Clin proc. 2010;85(1):53-62. doi:10.4065/ mcp. 2009.0248

40. Ho A. Relational autonomy or undue pressure? Family's role in medical decision-making. Scand J Caring Sci. 2008;22(1):128-135. doi:10.1111/j.1471-6712.2007.00561.x

\section{Publish your work in this journal}

Patient Preference and Adherence is an international, peer-reviewed, open access journal that focusing on the growing importance of patient preference and adherence throughout the therapeutic continuum. Patient satisfaction, acceptability, quality of life, compliance, persistence and their role in developing new therapeutic modalities and compounds to optimize clinical outcomes for existing disease states are major areas of interest for the journal. This journal has been accepted for indexing on PubMed Central. The manuscript management system is completely online and includes a very quick and fair peer-review system, which is all easy to use. Visit http:// www.dovepress.com/testimonials.php to read real quotes from published authors. 